\title{
En memoria del licenciado Héctor Manuel de León Hernández
}

(25 de septiembre de 1949 - 29 de febrero de 2016)

Departamento de Formación y Actualización Académica

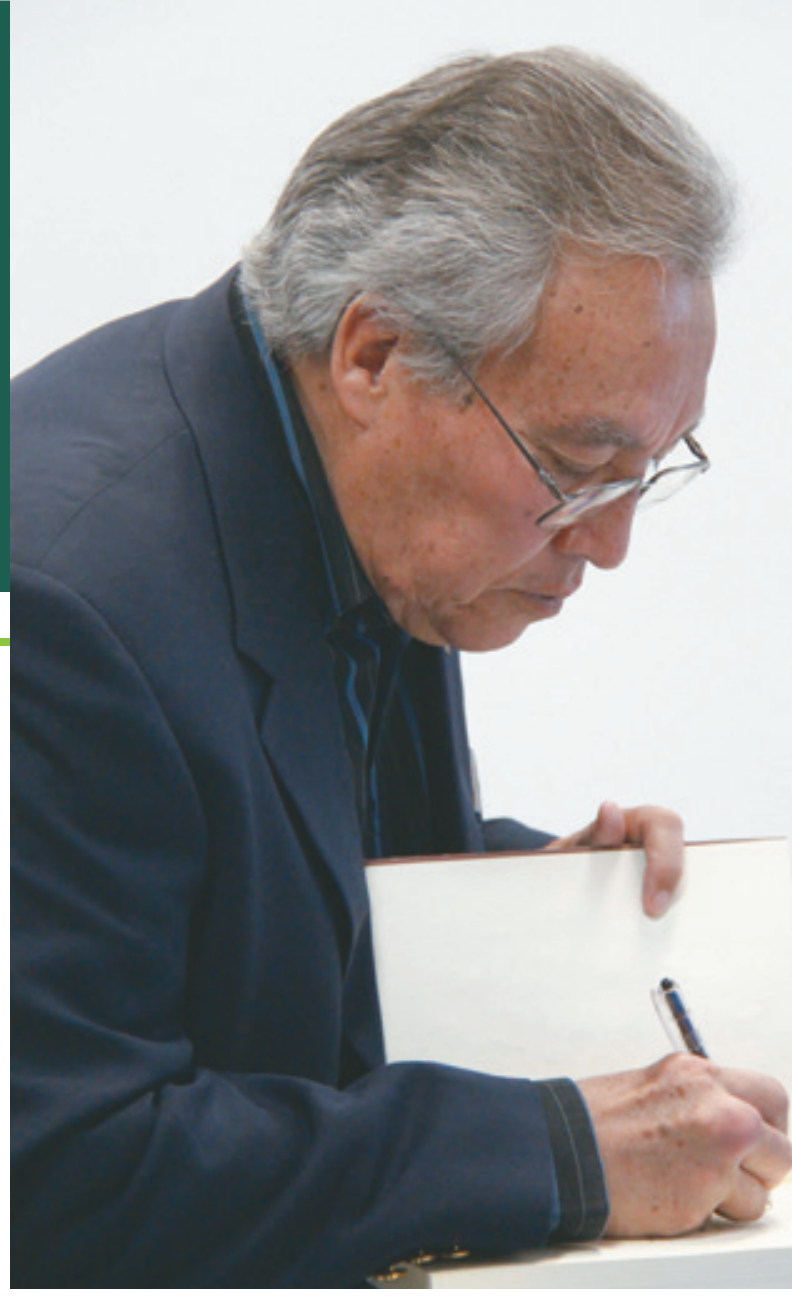

Laboró en la Universidad Autónoma de Aguascalientes (UAA) desde su fundación, durante 41 años, en la cual desempeñó diversas funciones entre las que destacan el cargo de Jefe de Departamento de Comunicación y Relaciones Públicas, Jefe de la Sección de Publicaciones del mismo, Jefe de Radio Universidad y, finalmente, Asesor de la Rectoría.

Otros puestos públicos que ocupó fueron: Jefe del Departamento de Difusión de la Delegación de la Secretaría de Educación Pública en Aguascalientes, Jefe de Comunicación y Relaciones Públicas del Patronato de la Feria Nacional de San Marcos, Coordinador de Comunicación y Relaciones Públicas de la Romería de la Asunción.

Es reconocido por su trabajo como cronista de la UAA por sus diversas publicaciones, entre las que se encuentran:

1. El principio ... el inicio de la Universidad Autónoma de Aguascalientes y la relación con sus académicos.

2. Campus Sur y Bachillerato Oriente, una realidad.

3. Proyecto original de la Universidad Autónoma de Aguascalientes 1973.

4. Memoria. Pasado, presente y futuro de la Universidad Autónoma de Aguascalientes.

5. 60 años de autonomía.

6. Fundación de la UAA. Historia gráfica 19721977.

7. Cien años del Instituto de Ciencias de Aguascalientes (2 tomos).

8. Cuatro décadas.

9. Memorias Institucionales, periodo 19721977 (6 tomos).

10. Memorias Institucionales, periodo 19781980.

11. Memorias Institucionales, periodo 19811983 (2 tomos).

12. Memorias Institucionales, periodo 19841989 (6 tomos).

13. Memorias Institucionales, periodo 19901995 (2 tomos).

14. Memorias Institucionales, periodo 20052010 (2 tomos). 
Además de los libros antes referidos publicados como autor, realizó ocho más como coautor, financió las ediciones de tres revistas, y fue conductor de programas tanto de radio como de televisión. En el número ocho de la revista Docere, publicó el artículo "Cuarenta años y se mantiene la ilusión", en el cual se conmemoró el 40 aniversario de la UAA.

$\mathrm{Su}$ legado será siempre un referente fundamental para el rumbo y crecimiento de la institución, y su huella imborrable, cumplió la gran meta que le fue encomendada. Descanse en paz.
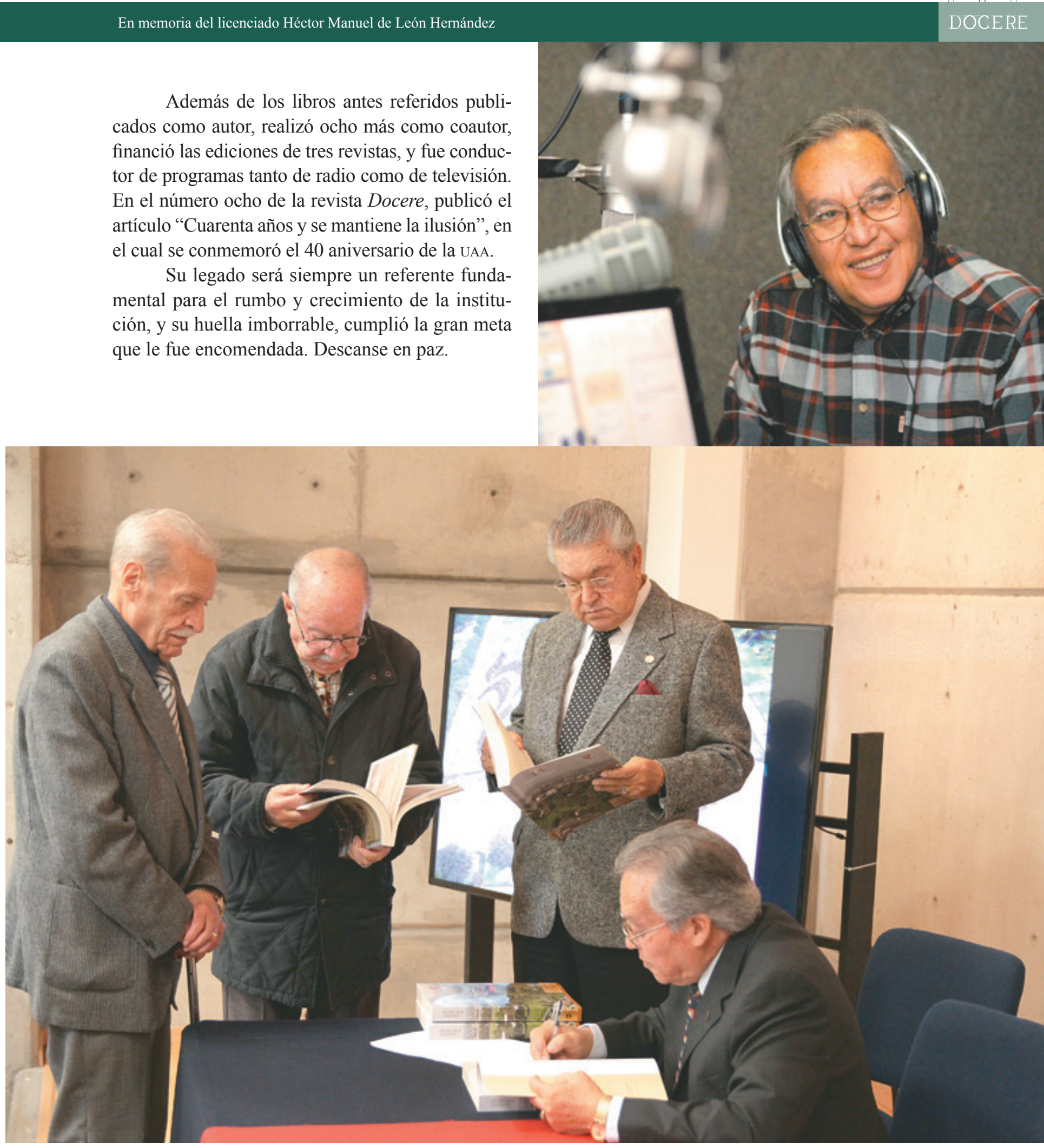

Agradecemos al licenciado Francisco Javier Franco Vargas, Asistente de Rectoría, la información proporcionada para la elaboración de este artículo, así como a la maestra María Teresa de León Gallo, encargada del Procesos de Evaluación en el Departamento de Evaluación Educativa, por la revisión del mismo. 